\title{
Jogos educativos: \\ Experiência do Città nas escolas secundárias moçambicanas
}

\author{
Armando Zavala, PGIE/UFRGS, zavalove@live.com \\ Margarete Axt, PGIE/UFRGS, maaxt03@gmail.com \\ Eliseo Reategui, PGIE/UFRGS, eliseoreategui@gmail.com
}

\begin{abstract}
Resumo: $O$ ensino e aprendizagem quando mediado por jogos educativos, pode trazer uma série de benefícios que possam enriquecer as aulas. O Città torna-se num jogo educativo que busca (novas) formas de ensinar e aprender, com metodologias alternativas de produção e in(ter)venção, para atender adequadamente às necessidades da sociedade. Este artigo apresenta o potencial dos jogos digitais educacionais, baseado na experiência obtida da implementação do Ci(ttà)vitas com alunos da $8^{a}$ classe em Moçambique. Estas experiências foram relatadas com base nas discussões apresentadas na sala de aulas sobre os problemas sociais que assolam as cidades, onde o simulador Città contribuiu através dos seus princípios na reflexão sobre a construção de um Maputo sustentável. Foram aprendidas lições com o Città durante esta experiência e categorizadas em quatro níveis de aprendizado.
\end{abstract}

Palavras-chaves: jogos educativos, projeto civitas, simulador città

Abstract: The teaching and learning when mediated by educational games can bring a lot of benefits that can enrich the lessons. The Città becomes an educational game, which uses new ways of teaching and learning, with alternative methods of production and intervention and can adequately meet the needs of society. This paper presents the potential of educational digital games based on the experience gained from the implementation of the Civitas with grade 8 students in Mozambique. These experiences have been reported based on the discussions presented in the classroom about the social problems, which devastate the cities, where the Città simulator has contributed by its principles in thinking about building a sustainable Maputo city. Lessons gained from the Città during this experience have been categorized into four levels of learning.

Keywords: educational games, civitas project, simulator città.

\section{Introdução}

Os jogos educativos são um meio importante pelo qual nossos alunos estão aprendendo, preparando-se para a vida no século XXI (Aldrich, 2009). As crianças de hoje querem ser envolvidas, e os jogos não só as envolvem, mas também ensinam lições valiosas durante o processo - lições que nós queremos que elas aprendam (Prensky, 2010). Entre esses jogos temos o "Città", escopo deste trabalho, o qual traz uma experiência da in(ter)venção feita com alunos da $8^{\mathrm{a}}$ classe em Moçambique, explorando o aporte das tecnologias com conteúdos digitais, enquanto inseridas numa dimensão (est)ético e político, configurada no pensamento crítico-analítico, na cooperação social, na preservação ambiental, na escuta e no respeito à diferença. 
O Città é um jogo educativo, voltado a simulação de cidades tridimensionais no computador. Ele atua, basicamente, como uma versão digital das maquetes construídas por estudantes do quarto ano do ensino fundamental (Axt, et al 2014). A simulação de cidades foi utilizada por Martins (2009) num estudo que deu origem a sua tese de Doutorado, em que alunos simularam cidades baseando em experimentações que aconteciam em torno de maquetes: bairros, distritos, meio rural, meio urbano, com representação de outros sistemas acoplados à cidade/município, tais como o transporte, a hidrografia, o trânsito. Os resultados desse estudo, permitiram uma associação por semelhança entre o currículo convencional (terceira série), caraterizado pelo estudo do município e a proposta de inventar uma cidade.

Neste trabalho, pretende-se apresentar um estudo sobre jogos digitais educativos e as discussões provocadas pela invenção de cidades imaginárias com o jogo educativo Città, implementado na Escola Secundária Quisse Mavota-Cidade de Maputo, Moçambique. A proposta se configura como uma in(ter)venção que desafia os alunos a repensar nas suas ações, contribuindo para a construção de uma cidade sustentável enquanto cidadãos comprometidos com a promoção e preservação da vida.

\section{Jogos digitais educativos}

Os jogos digitais são considerados como ambientes atraentes e interativos que capturam a atenção do jogador ao oferecer desafios que exigem níveis crescentes de destreza e habilidades (Balasubramanian e Wilson, 2006).

Não basta ter um jogo digital e pensar-se que ele é um instrumento educativo. É necessário que o jogo contenha ainda, algumas características específicas para atender as necessidades vinculadas à aprendizagem. Axt et al (2008) reforçam que eventualmente, pode ocorrer de um software educacional ser projetado e construído intencionalmente para ter a forma de um jogo, mas não atender a alguma dessas características propostas. Isso geralmente ocorre devido a um foco excessivo nos conteúdos pedagógicos ao invés de focar na estrutura (regras) e na dinâmica de jogo, descaracterizando o produto final e por vezes comprometendo seu potencial em termos de motivação e engajamento do jogador.

Por isso, Prieto (2005) argumenta que os jogos educativos devem possuir objetivos pedagógicos e a sua utilização deve estar inserida em um contexto e em uma situação de ensino baseados em uma metodologia que oriente o processo, através da interação, da motivação e da descoberta, facilitando a aprendizagem de um conteúdo. Axt et al (2008) acrescentam que o jogo educativo é projetado para atender a objetivos de ensino e aprendizagem geralmente relacionados a um domínio de conhecimentos curriculares. Isso faz com que o projeto e desenvolvimento desse tipo de software demandem o envolvimento de uma equipe multidisciplinar, da qual podem fazer parte pedagogos, psicólogos, especialistas no domínio, designers de jogos, engenheiros de software, programadores, especialistas em interação humano-computador, entre outros.

Os jogos educativos com finalidades pedagógicas revelam a sua importância, pois promovem situações de ensino-aprendizagem e aumentam a construção do conhecimento, introduzindo atividades lúdicas e prazerosas, desenvolvendo a capacidade de iniciação e 
ação ativa e motivadora. "A estimulação, a variedade, o interesse, a concentração e a motivação são igualmente proporcionados pela situação lúdica...” (Moyles, 2002).

A partir dos jogos educativos é possível criar um ambiente de ensino atrativo e agradável. Combinando mecanismos de entretenimento e educação, tornam-se num recurso pedagógico no qual educadores podem se apoiar para a realização de aulas mais dinâmicas, mudando o tradicional modelo de ensino que já não surte grande empolgação nos aprendizes (Tarouco, et al, 2004). Assim, Falkembach e Geller (2006) justificam que os mesmos possibilitam reforçar os conteúdos estudados, despertando o interesse dos alunos, auxiliando no desenvolvimento do raciocínio lógico, potencializando a aprendizagem, facilitando a construção do conhecimento de forma prazerosa $\mathrm{e}$ propiciando uma forma diferenciada de aprendizagem.

As crianças quando jogam um game, aprendem em situações em que muitas coisas estão acontecendo simultaneamente e mesmo assim, elas conseguem identificar e se concentrar no que é mais importante, deixando o resto de lado (Prensky, 2010). Até porque ninguém explica antes às crianças sobre as regras de seus jogos. Elas descobremnas à medida que vão jogando. Os pesquisadores da ciência dizem que quem joga um game, aprende a deduzir as regras do jogo a partir dos fatos que observa e estes jogadores de game (Savi e Ulbricht, 2008) tornam-se experts no que o jogo propõe. Isso indica que jogos com desafios educacionais podem ter o potencial de tornar seus jogadores experts nos temas abordados

Alguns autores como Kishimoto (1996) e Grando (2001) criticam a inserção dos jogos digitais educativos no contexto de ensino e aprendizagem. As críticas resultam pelo fato de existir o perigo de se dar ao jogo um caráter puramente aleatório, tornando-se um "apêndice" em sala de aula. Sendo que alunos jogam e se sentem motivados apenas pelo jogo, sem saber porque jogam. Gasta-se maior parte do tempo com atividades do jogo em sala de aulas e, se o professor não estiver preparado, pode existir um sacrifício de outros conteúdos pela falta de tempo. Também existem falsas concepções de que se devem ensinar todos os conceitos através de jogos. Então as aulas, em geral, transformam-se em verdadeiros cassinos, também sem sentido algum para o aluno. Falkembach (sd), acrescenta críticas aos jogos, sendo algumas delas, a interferência com frequência do professor que origina na perda da "ludicidade" do jogo; se o aluno for obrigado a jogar por exigência do professor, o aluno fica contrariado e se as regras não forem bem entendidas pelos alunos, eles ficam desorientados.

A pesar dessas desvantagens aos jogos digitais educativos, consideramos que são passíveis de correção por isso alinhamos com autores como Axt et al (2008), que consideram necessários para o ensino e aprendizagem porque para além de educar, um jogo educativo também tem a componente "diversão". A diversão é a tal que estimula a aprendizagem e incita também a resolução dos problemas propostos, permitindo ao utilizador raciocinar e estimular as suas capacidades cognitivas, assim como desenvolver a sua coordenação motora e reflexiva.

Consequentemente, a Axt et al (2008) alertam que os idealizadores de jogos educacionais devem estar atentos também para garantir esse aspecto - da livre exploração por parte do jogador - oferecendo uma dinâmica de jogo que garanta ao aprendiz jogador a faculdade de aprender enquanto joga, ao invés de estritamente jogar para aprender. 
Esta alerta é ao mesmo tempo uma tentativa de seduzir ao caro leitor deste trabalho e direcioná-lo para o caminho de aceitação ou ao menos de experimentação do simulador Città como um jogo educativo que apoiará no desenvolvimento ou aprimoramento de capacidades que refletirão diretamente no processo de ensinar e aprender, o que a seguir se descreve.

\section{O simulador Città no contexto dos jogos educativos}

O Città surge em 2002 no Projeto CIVITAS ${ }^{1}$ como proposta de desenvolvimento de um editor online de cidades, de responsabilidade do grupo de pesquisa do Laboratório de Estudos da Linguagem, Interação e Cognição (LELIC), da Universidade Federal do Rio Grande do Sul (UFRGS).

CIVITAS é, na verdade, um projeto na forma de experimentações em sala de aula envolvendo professores e alunos do Ensino Fundamental ( $3^{\mathrm{a}}$ série), equipe de pesquisadores e bolsistas, além de estudantes da pós-graduação e de estudantes da graduação em Pedagogia (em disciplina optativa). Um projeto que tem expectativa de poder pensar-sentir-pesquisar a Cidade Viva, em conjuntopesquisadores, bolsistas, estudantes envolvidos (do Ensino Superior), professores e crianças - numa relação de acolhimento à diversidade de posições e aos tempos de construção do conhecimento, inaugurando uma aprendizagem pautada na produção coletiva de sentidos e pela reciprocidade. Pretende constituir, ao lado de outros, um espaço alternativo de acontecimento-invenção na escola (Axt, 2004)

As cidades virtuais - estando propostas no âmbito das tecnologias digitais (mas não excluindo cidades com materiais e suportes convencionais concretos) - supõem uma produção coletiva de sentidos, levando a uma construção negociada e cooperativa de significados estáveis (conceituais), em tempo real, tanto síncrono quanto assíncrono, pelos vários grupos de crianças e suas professoras, em uma relação de reciprocidade. É, portanto, de se esperar que precisem discutir regras de construção, desde a definição do terreno, a aprovação de um plano diretor em função do próprio terreno, a distribuição de lotes para a construção de casas e prédios, até a definição de uma legislação de preservação ambiental, envolvendo a organização social, política e jurídica da cidade, a memória cultural-histórica, a posição econômico-geográfica relativa (na região, no país e no plano mundial) e o estabelecimento de contratos sociais coordenando as relações de sociabilidade entre os cidadãos, ou seja, entre elas (as próprias crianças) (Axt, 2004).

O Città tornou-se numa ferramenta metodológica dentro do Projeto CIVITAS ${ }^{2}$ onde são desenvolvidas novas metodologias que utilizam diferentes tecnologias que coexistem na sala de aula. À medida que a criança vai construindo cidades virtuais pelo editor Città, aprende para além de outras coisas, tomar decisões morais e de valores.

Segundo Axt et al (2008), o Projeto CIVITAS enfoca jogos educacionais colaborativos com a finalidade de compartilhar um entendimento ou resolver um problema, cujo o tal entendimento se refere às ações e estratégias que são desenvolvidas

\footnotetext{
${ }^{1}$ Cidades Virtuais e Tecnologias para Aprendizagem e Simulação

${ }^{2}$ Como o CIVITAS objetiva a formação em serviço de professores para a aplicação de metodologias dentro da coexistência de diferentes tecnologias, o Città foi construído para ser uma ferramenta de inclusão digital dentro desse processo (Texto disponível em: http://cosmopolita.conexum.com.br/ acesso em: 16 de outubro de 2015).
} 
pelos jogadores e o problema se refere a vencer ou contornar, coletivamente, os desafios e obstáculos oferecidos pelo jogo educacional. Por exemplo, quando os professores do CIVITAS propõem uma tarefa para ser realizada com o Città, este impõe limitações de recursos ou tarefas conflitantes aos jogadores, que necessitam ser resolvidas. Desta forma, se tem um processo de socialização, cooperação e aprendizado.

O Città é contextualizado dentro da linha de jogos de civilização, onde o jogo proporciona a conquista do espaço e construção da infraestrutura necessária para a subsistência da população (Huber, 2008). No entanto, o Città diferencia-se de muitos jogos comerciais que estão direcionados para denominação de povos, mas este, para construção de uma cidade, mais próximo ao Simcity ${ }^{3}, \mathrm{Caesar}^{4}$ ou Pharaoh $^{5}$ (ambos da Impressions Games).

Todos estes jogos incluindo o Città são softwares livres que se destinam a construção e gestão de uma cidade em um ambiente de jogo em aberto e podem ser adaptados às necessidades educativas curriculares e de cidadania. Mas o Città leva vantagem por ser um software menos complexo que não acarreta custos monetários para a sua aquisição e utilização, contrariamente aos outros. Além disso, é um software multiusuário que agrega recursos, permitindo uma construção em tempo real de vários jogadores sobre a mesma cidade e, funciona em ambiente de rede de computadores que executam o Windows Multipoint Server 2011. Também é o único software que tem recursos como edifícios, paisagens (cor verde) e estradas que se aproximam a realidade de Moçambique.

Em suma, as vantagens do Città aqui destacadas justificam a nossa opção por este software como um jogo educativo. Assim, começa-se a despertar o interesse por (novas) metodologias alternativas de produção e in(ter)venção, e vamos tentar instigar um pouco esse interesse no próximo tópico com a apresentação da experiência realizada com alunos da $8^{\text {a }}$ classe em Moçambique.

\section{Experiência do Città na Escola Secundária Quisse Mavota}

O Città sendo um jogo educativo em um ambiente de interação social no espaço virtual, foi utilizado num estudo realizado na Escola Secundária Quisse Mavota - Cidade de Maputo, Moçambique. O mesmo foi realizado num período de seis meses (fevereiro a julho de 2015) envolvendo 87 alunos (duas turmas) da $8^{\text {a }}$ classe, divididos em quatro grupos de 20 a 22 alunos cada (metade da turma). Estes grupos, por sua vez foram subdivididos em grupos de trabalho de 2 a 3 alunos. A atividade consistia em "discutir políticas públicas sustentáveis que respeitam e preservam o meio ambiente a partir dos princípios do Città”. Estes princípios são: cooperação, trabalho coletivo, preservação do ambiente, respeito por si, pelo outro e pela vida. Em seguida, empregou-se o simulador Città para representar "cidades imaginárias" resultantes das discussões sobre políticas públicas sustentáveis. Esta representação foi feita em ambiente de rede de computadores que executam o Windows Multipoint Server 2011.

\footnotetext{
${ }^{3}$ Disponível em: http://www.simcity.com/ acesso em: 29 de outubro de 2015

${ }^{4}$ Disponível em: http://www.gamespot.com/caesar-iv/ acesso em: 29 de outubro de 2015

${ }^{5}$ Disponível em: http://pharaoh.heavengames.com/ acesso em 29 de outubro de 2015
} 
A figura abaixo mostra o exemplo de uma cidade imaginária construída por um grupo de 2 alunos durante a intervenção.

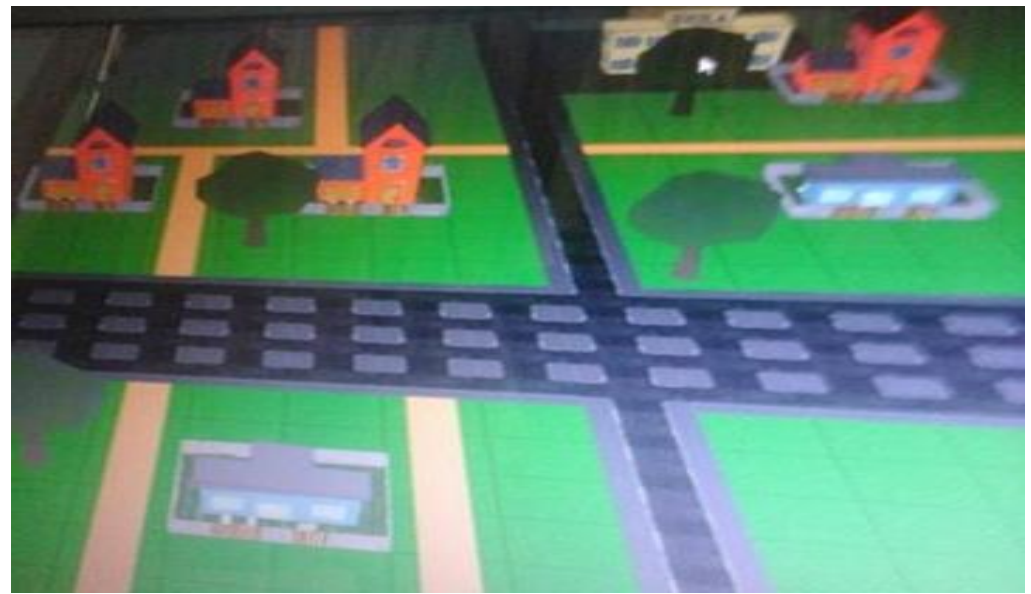

Figura 01: Cidade imaginária construída pelos alunos.

Nas discussões, tomou-se como base os problemas sociais das cidades, com o exemplo da Cidade de Maputo. Desse modo, os alunos fizeram o levantamento dos problemas que assolam a cidade de Maputo junto às suas comunidades, tendo sido destacados alguns:

Quadro 01: Problema apresentado pelo sujeito-A

\section{Sujeito A - $8^{\text {a }}$ classe, Turma 1}

Habitação - há falta de espaços para a construção de casas para os jovens devido ao não ordenamento territorial aquando a expansão da cidade.

Por isso, acho que o Conselho Municipal deve expandir mais a cidade e para os bairros não parcelados na cidade deve se fazer um (novo) parcelamento para expandir a iluminação pública, e que pode melhorar a segurança pública no período noturno.

A proposta apontada pelo sujeito-A abriu o horizonte nos alunos para se pensar nas ferramentas do Città e com estas, representar cidades imaginárias com uma estrutura que apresente construções de casas em bairros parcelados. Provavelmente tenha sido uma atividade que ficou marcada nas suas vidas porque a maioria dos alunos vivem em bairros não parcelados.

No quadro 2, destaca-se o problema apresentado pelo sujeito-B. O desafio decorrente deste problema foi de representar cidades imaginárias contendo bairros residenciais, zonas comerciais e zonas industriais. Isso foi possível devido a colaboração entre os alunos, tendo culminado com sucessos na atividade proposta.

Quadro 02: Problema apresentado pelo sujeito-B

\section{Sujeito B $-8^{\text {a }}$ classe, Turma 1}


Poluição do meio ambiente - existem empresas construídas em bairros residenciais que poluem o meio ambiente e a maior lixeira da cidade encontra-se numa zona residencial (bairro de Hulene).

Penso que o Conselho Municipal não devia ter autorizado o funcionamento de empresas industriais nos bairros residenciais porque não só prejudicam o meio ambiente, mas também é um atentado à saúde pública.

Percebeu-se também que o problema declarado pelo sujeito-B conduziu a turma sobre a necessidade de se pensar numa cidade com políticas que preservam e respeitam o meio ambiente.

A seguir, distingue-se o problema apresentado pelo sujeito-C.

Quadro 03: Problema apresentado sujeito-C

Sujeito C - $8^{\text {a }}$ classe, Turma 2

Doenças - existem muitas doenças que resultam da fraca sanidade do meio, como o caso da cólera e malária que são causadas por lixo que eles próprios (comunidade) produzem e que depositam em lugares inadequados.

Acho que o Conselho Municipal devia aumentar contentores de lixo, principalmente em bairros de expansão e garantir a sua recolha diária pois esta é feita uma ou duas vezes por semana. $\mathrm{O}$ sujeito $\mathrm{C}$ até questionou a finalidade da taxa de lixo que a população é cobrada nas recargas de energia. Fato que não justifica que hajam poucos contentores de lixo na cidade, e em consequência disso, o lixo é depositado em lugares inadequados - frisou o sujeito $\mathrm{C}$.

O problema levantado pelo sujeito-C, deixou clara a necessidade de manter a cidade limpa, onde as instituições responsáveis (Conselho Municipal) tenham um papel importante na sua gestão. As cidades imaginárias representadas pelos alunos também respondiam a este desafio.

No quadro a seguir, destaca-se o problema apresentado pelo sujeito-D. Com este problema, pensou-se em cidades com transportes públicos suficientes para transportar pessoas para os seus destinos e com inúmeras possibilidades de estradas alternativas para o acesso ao centro das mesmas.

Quadro 04: Problema apresentado sujeito-D

\section{Sujeito D - ${ }^{\text {a }}$ classe, Turma 2}

Transporte - há problemas sérios de transporte, principalmente nas primeiras horas e no final do dia, fato que faz com que as pessoas sejam transportadas por carros de caixa aberta.

O Conselho Municipal devia aumentar autocarros públicos (ônibus) porque os existentes não cobrem com a demanda da população, fato que leva com que as pessoas sejam transportadas em carros de caixa aberta, os vulgos "my love", o que é "vergonhoso" para uma cidade capital de um país. O sujeito-D sublinhou que os alunos 
sempre chegavam tarde à escola e que na maioria dos dias não assistiam o primeiro tempo (7:00horas) devido a carência de transporte, associada ao tráfego automóvel intenso na hora de ponta. Por isso, o Conselho Municipal devia reabilitar e construir estradas alternativas que dão acesso ao centro da cidade porque as estradas existentes não fazem cobertura ao crescente aumento do parque automóvel na cidade.

Fica evidente nestes quatro exemplos o esforço dos alunos em apresentar propostas de soluções face aos problemas encontrados nas suas comunidades e representar cidades imaginárias sustentáveis com as ferramentas do Città. Mas cabe destacar aqui que o mesmo pôde ser observado na maior parte dos problemas apresentados pelo grupo de 87 alunos.

\section{Lições aprendidas com Città em relação à construção da cidade sustentável}

Como se fez referência antes que o Città é um jogo educativo, o seu objetivo principal consiste em criar um ambiente cooperativo e construtivo para a simulação de cidades tridimensionais através de uma interface computacional gráfica para uma aplicação multiusuário. Partindo deste objetivo (do Città), os alunos foram simulando cidades imaginárias, contornando os obstáculos encontrados nas discussões. Sendo que muitas coisas eles discutiram, e algumas delas vamos categorizar em níveis do aprendizado a saber: Como, $\mathrm{O}$ quê, Onde e Se.

No nível de aprendizado "Como", os alunos discutiram estratégias de comportamento em sociedade que preserva o seu meio ambiente, de sustentabilidade, que pauta pelo respeito a si, pelo outro e pela vida. Este respeito foi mediado pelo diálogo numa atitude responsiva (Bakhtin 2003, p.382) do eu-para-mim, eu-para-o-outro e ooutro-para-mim. Em outro nível “Como”, os alunos debateram estratégias para planejar diferentes ações macro, levando em consideração o interesse de um bairro, distrito, de setor (saúde, educação, trânsito, empresas, etc), ou ainda, de uma determinada classe social.

Para o nível de aprendizado " $\boldsymbol{O} \boldsymbol{q u} \hat{\boldsymbol{e}}$ ”, os alunos definiram regras para o mapeamento das reais necessidades da cidade, dando prioridade às carências dos bairros, distritos municipais, setores de produção, etc. Em outro nível "O quê", os alunos definiram políticas públicas sustentáveis que respeitam e preservam o meio ambiente. É nesse espaço singular que alunos vivem, lidam-se com saberes culturais e constroem as suas histórias de vida em uma interação direta e saudável com o meio ambiente, como nos ensina o Bakhtin:

Todo ato cultural vive por essência sobre fronteiras, sem estas, ele perde terreno, torna-se vazio, pretensioso, degenera e morre. [...]. Enfim deve-se dizer que nenhum ato vive nem se movimenta no vazio, mas na atmosfera valorizante, tensa, em um mundo vivo e significante, assim proporcionando e proporcionado pela cultura em determinado tempo e espaço (Bakhtin, 2002, p. 29-30).

No nível do contexto "Onde", os alunos discutiram um pouco sobre a história da cidade de Maputo, sua divisão administrativa (distritos urbanos, bairros), algumas empresas, serviços de saúde, educação, saneamento ambiental, lazer, entre outros. Discutiram também políticas para que a cidade de Maputo tenha um estilo de vida mais sustentável porque muitos foram os pontos negativos encontrados, que são obstáculos para a própria vida das pessoas. 
Para o último nível de aprendizado, o nível "Se" que foi considerado de nível (est)ético e político, eles (alunos) refletiram em certas decisões morais e de valores. Bakhtin (2003) substancia o ético como parte integrante do objeto estético, o conteúdo profundo de uma obra, que envolve, além dos elementos estéticos, também elementos éticos e cognitivos, todos, porém, com coeficiente estético. Tal que os alunos debateram sobre as consequências de suas escolhas na vida, desde pequenas escolhas até as grandes escolhas. É interessante que as crianças começaram a pensar numa cidade dos seus sonhos, com comunidades economicamente equilibradas, socialmente justas e ambientalmente corretas, e para lá chegarem, pensaram num exercício de cidadania a partir dos princípios do Città.

\section{Considerações finais}

A partir deste trabalho foi possível verificar que o jogo educativo Città criou uma oportunidade para os alunos da Escola Secundária Quisse Mavota, refletir sobre os problemas sociais das cidades, propondo soluções para tornar Maputo numa cidade sustentável partindo dos princípios do Città (cooperação, trabalho coletivo, preservação do ambiente, respeito por si, pelo outro e pela vida).

Para além do jogo ser educativo e proporcionar uma maneira divertida de aprender, o simulador Città criou ainda espaço para partilha de ideias resultando numa aprendizagem colaborativa e cooperativa. Foi predominante também a interação dos alunos com os recursos que compõem o jogo, caso concreto de casas, escolas, estradas, árvores, pessoas, e de mais recursos que são uma grande porção de atratividade dele.

O maior trunfo que atraiu os alunos que ainda tinham receios quanto a utilização do simulador Città em contexto educativo foi a facilidade do seu acesso e uso em ambiente de rede de computadores na construção de cidades tridimensionais, o que tornou a aprendizagem mais envolvente.

O estudo permitiu concluir que o software pode ser uma alternativa tecnológica com potencial para enriquecer as aulas, devido a sua natureza que possibilita a discussão de conceitos relevantes que resgatam inclusive histórias e/ou experiências dos próprios alunos. Tal possibilidade permite ao professor trabalhar com determinado conceito, ao mesmo tempo em que propõe a sua simulação.

\section{Referências}

ALDRICH, Clark (2009). Learning online with games, simulations and virtual worlds. San Francisco, CA, Jossey-Bass.

AXT, M., FERREIRA FILHO, R. C. M., BAlle, E. E., MÜLlER, D. N. (2008). Cidades Virtuais: tecnologias para aprendizagem e simulação. IV SEMINÁRIO JOGOS ELETRÔNICOS, EDUCAÇÃO E COMUNICAÇÃO: construindo novas trilhas. Salvador: UNEB, v.1. pp. 1-10.

AXT, Margarete (2004). CIVITAS, a Cidade Viva: ou do espaço de invenção do educador na escola.

AXT, Margarete; MÜLLER, Daniel Nehme e HETKOWSKI, Tânia Maria (2014). Cultura digital e espaço escolar: diálogo sobre Jogos, Imaginário e Crianças. Salvador. 
BALASUBRAMANIAN, Nathan; WILSON, Brent G. Games and Simulations. In: SOCIETY FOR INFORMATION TECHNOLOGY AND TEACHER EDUCATION INTERNATIONAL CONFERENCE (2006). Proceedings...v.1. 2006. Disponível em: http://site.aace.org/pubs/foresite/GamesAndSimulations1.pdf . Acesso em: 16 de outubro de 2015.

BAKHTIN, Mikhail Mikhailovich (2003). Estética da Criação Verbal. Tradução do russo Paulo Bezerra. 2. ed. São Paulo: Martins Fontes.

BAKHTIN, Mikhail (2002). Questões de Literatura e de Estética: a Teoria do Romance. 5a. ed. São Paulo-SP: Editora Hucitec e Anablume. Equipe de Tradução do Russo: Aurora Fornoni Bernardini; José Pereira Júnior; Augusto Góes Júnior; Helena Spryndis Nazário e Homero Freitas de Andrade.

FALKEMBACH, G. A. M. and Geller, M. (2006). Desenvolvimento de Jogos Educativos Digitais utilizando a Ferramenta de Autoria Multimídia: um estudo de caso com o Toolbook Instructor.

FALKEMBACH, G. A. M. O lúdico e os jogos educacionais. Mídias na Educação. CINTED- UFRGS.

GRANDO, R. C. (2001) O jogo na educação: aspectos didático-metodológicos do jogo na educação matemática. Unicamp.

HUBER, N. (May 2008). Coming Attractions. School Library Journal v. 54 no. 5.

KISHIMOTO, T. M. (1996). Jogo, Brinquedo, Brincadeira e a Educação. São Paulo: Cortez.

MARTINS, Márcio André Rodrigues (2009). Projeto Civitas: (multi)(pli)cidades e as interveRsões do tempo na sala de aula Ensino Fundamental. Porto Alegre. Tese (Doutorado em Educação) - Pós-Graduação em Educação, Faculdade de Educação, Universidade Federal do Rio Grande do Sul, Porto Alegre.

MOYLES, Janet R. (2002) Só brincar? O papel do brincar na educação infantil. Tradução: Maria Adriana Veronese. Porto Alegre: Artmed.

PRENSKY, Marc (2010). "Não me atrapalhe, mãe- Eu estou aprendendo! ”. Como os videogames estão preparando nossos filhos para o sucesso no século- e como você ajudar! São Paulo.

PRIETO, Lilian Medianeira et al. Uso das Tecnologias Digitais em Atividades Didáticas nas Séries Iniciais. Renote: revista novas tecnologias na educação, Porto Alegre, v. 3, n. 1, p.1-11, maio 2005. Disponível em:

http://www.cinted.ufrgs.br/renote/abril2015/artigos/a6_seriesiniciais_revisado.pdf,

Acesso em: 10 de outubro 2015.

TAROUCO, L. M. R., Roland, L. C., Fabre, M.-C. J. M., and Konrath, M. L. P. (2004). Jogos educacionais.

SAVI, Rafael e ULBRICHT (2008), Vania Ribas Jogos Digitais Educacionais: Benefícios e Desafios, Novas Tecnologias na Educação, CINTED-UFRGS.

VANDEVENTER, S. S. WHITE, J. A. (2002). Expert Behavior in Children's Video Game Play. Simulation Gamin. Dispoível em: <http://www.slideshare.net/pedic/jogosdigitais-educacionais-e-educao-cientfica-reconhecendo >. acesso em 19 de outubro de 2015.

\section{Sites consultados}

http://cosmopolita.conexum.com.br/

http://www.simcity.com/

http://www.gamespot.com/caesar-iv/

http://pharaoh.heavengames.com/ 